\title{
Penerapan Diet Hipertensi pada Masyarakat Kelurahan Legok
}

\author{
Ariyanto ${ }^{1}$, Tina Yuli Fatmawati ${ }^{2}$ \\ ${ }^{1,2}$ Program Studi DIII Keperawatan STIKes Baiturrahim Jambi \\ Email : riyan.stikba@gmail.com
}

Submitted : 08/01/2022

Accepted: 10/01/2022

Published: 28/01/2022

\begin{abstract}
Hypertension is one of the main problems in society in Indonesia and the world. It is estimated that around $80 \%$ of the increase in hypertension cases mainly occurs in developing countries in 2025 from a total of 639 million cases in 2000. This number is estimated to increase to 1.15 billion cases in 2025. This prediction is based on the number of people with hypertension and current population growth. The initial survey in January 2021, a survey conducted on one resident said he was still accustomed to an unhealthy lifestyle such as frequently consuming fatty foods, coconut milk, fried foods, smoking habits in men, lack of exercise and lack of understanding how to prevent hypertension. The purpose of this service is so that the community understands how to implement the Hypertension Diet in the Legok Village community, Jambi City. This service is carried out during the even semester from March-August 2021 at RT 037 Kel. Legok Danau Sipin, 15 participants participated. The method used is lecture, discussion and question and answer with leaflet and module media, physical examination tool is Tensimeter. The results of the activity obtained that all participants were able to understand how to apply the hypertension diet. Participants will also try to maintain/regulate eating patterns, avoid stress, also do physical activities and check blood pressure regularly
\end{abstract}

Keywords: diet, hipertension, healthy life

\begin{abstract}
Abstrak
Hipertensi menjadi salah satu masalah utama pada masyarakat di Indonesia maupun dunia. Diperkirakan sekitar $80 \%$ kenaikan kasus hipertensi terutama terjadi di negara berkembang pada tahun 2025 dari jumlah total 639 juta kasus di tahun 2000. Jumlah ini diperkirakan meningkat menjadi 1.15 miliar kasus ditahun 2025. Prediksi ini didasarkan pada angka penderita hipertensi dan pertambahan penduduk saat ini. Survei awal pada bulan Januari 2021, Survei yang dilakukan pada salah satu warga mengatakan masih terbiasa melakukan pola hidup tidak sehat seperti sering mengkonsumsi makanan yang berlemak, bersantan, makanan yang digoreng, kebiasaan merokok pada Pria, kurang olahraga dan kurang memahami bagaimana pencegahan hipertensi. Tujuan pengabdian ini agar masyarakat memahami bagaimana Penerapan Diet Hipertensi pada masyarakat Kelurahan Legok Kota Jambi. Pengabdian ini dilaksanakan selama semester genap dari MaretAgustus 2021 di RT 037 Kel. Legok Danau Sipin, Peserta yang mengikuti sebanyak 15 orang. Metode yang digunakan ceramah, diskus dan tanya jawab dengan media leaflet dan modul, alat pemeriksaan fisik yaitu Tensimeter. Hasil kegiatan diperoleh seluruh peserta mampu memahami tentang bagaimana penerapan diet hipertensi. Peserta juga akan berusaha menjaga/mengatur pola makan, menghindari stress, juga melakukan aktifitas fisik dan melakukan cek tekanan darah secara berkala.
\end{abstract}

Kata Kunci: diet, hipertensi, hidup sehat

\section{PENDAHULUAN}

Hipertensi menjadi salah satu masalah utama dalam kesehatan masyarakat di Indonesia maupun dunia. Diperkirakan sekitar $80 \%$ kenaikan kasus hipertensi terutama terjadi di negara berkembang pada tahun 2025 dari jumlah total 639 juta kasus di tahun 2000. Jumlah ini diperkirakan meningkat menjadi 1.15 miliar kasus ditahun 2025. Prediksi ini didasarkan pada angka penderita hipertensi dan pertambahan penduduk saat ini (Ardiansyah, 2012). 
Prevalensi hipertensi di Indonesia pada kelompok usia 15-24 tahun adalah 13,2\% pada kelompok usia 25-34 tahun adalah 20,1\%, kelompok umur 35-44 tahun $31,6 \%$ usia $45-54$ tahun $45,3 \%$, usia55-64 tahun $55,2 \%$ untuk usia $65-74$ tahun $63,2 \%$ sedangkan lebih dari 75 tahun adalah $69,5 \%$, dengan prevalensi yang tinggi tersebut hipertensi yang tidak disadari jumlahnya bisa lebih tinggi lagi. Menghadapi pasien hipertensi diperlukan adanya kepatuhan perawatan diri mereka untuk meningkatkan derajat kesehatan. Perawatan diri hipertensi meliputi diet rendah garam, mengurangi konsumsi alkohol, tidak merokok, olahraga atau latihan fisik, dan konsumsi obat hipertensi.(Kemenkes RI, 2018).

Hipertensi ini merupakan penyakit yang tidak dapat disembuhkan namun hanya dapat dikendalikan. Pengendalian hipertensi merupakan sebuah proses yang rumit dan multidimensi. Pengendalian tersebut baik pada tingkat populasi maupun perorangan. Pada tingkat populasi, perubahan gaya hidup dengan menerapkan kerjasama antar sektor, melakukan pendekatan multidisiplin dan melibatkan masyarakat. Sedangkan pada tingkat perorangan dengan menggunakan metode non farmakologi dan farmakologi (WHO, 2001 dalam Rahajeng 2009).

Cara mengendalikan dan mencegah hipertensi, harus melakukan gaya hidup sehat. Hal ini sangat penting karena gaya hidup sehat akan membuat kita sehat keseluruhan dengan melakukan olahraga teratur, berhenti merokok juga berperan untuk mengurangi hipertensi, mengendalikan pola kesehatan secara keseluruhan, termasuk mengendalikan kadar kolestrol, diabetes, berat badan dan mengendalikan konsumsi makanan yaitu diet yang tepat. Jenis makanan tidak sehat yang dapat menyebabkan hipertensi yaitu makanan yang siap saji yangmengandung pengawet, kadar garam yangterlalu tinggi dalam makanan, kelebihankonsumsi lemak (Susilo dan Wulandari, 2011).

Menurut WHO(2013) menjelaskan penyakit kardiovaskular telah menyebabkan 17 juta kematian tiap tahun akibat komplikasi hipertensi yaitu sekitar 9,4 juta tiap tahun di seluruh dunia (AGlobal Brief on Hypertension, 2013).Prevalensi hipertensi di Indonesia pada usia $>18$ tahun sebesar $25,8 \%$.Terdapat 3 provinsi terbesar dengan kasus hipertensi yaitu Bangka Belitung(30,9\%), Kalimantan Selatan (30,8\%) dan Kalimantan Timur (29,6\%). SedangkanProvinsi Daerah Istimewa Yogyakarta (DIY) menempati urutan ke 14 denganprevalensi sebesar 25,7\% (Riskesdas, 2013).Prevalensi hipertensi terus meningkat salah satunya disebabkan oleh gayahidup yang tidak sehat seperti sering makan makanan fast food yang mengandungbanyak lemak dan makanan yang asin (Wahdah, 2011). Selain itu, kegemukan(obesitas), stres, merokok, dan mengkonsumsi alkohol juga dapat memicuterjadinya hipertensi (WHO, 2013). Hipertensi yang tidak ditangani dengan baik beresiko tinggi untuk terjadi komplikasi antara lain stroke, edema paru.

Kegiatan pengabdian ini sebelumnya juga telah dilaksanakan oleh tim pengabdian namun hanya berfokus pada penanganan hipertensi (Maimaznah \& Fatmawati, 2020). RT 037 Merupakan salah satu RT yang berada dalam Kawasan kelurahan legok Kecamatan Danau Sipin Kota Jambi Provinsi Jambi.Luas wilayah RT $37 * 0,0185 \mathrm{Km} 2$ jumlah penduduk 326 jiwa yang terdiri dari laki-laki 191 dan perempuan 135, terdiri dari berbagai macam suku diantaranya suku Melayu Jambi, Suku Palembang dan Suku Jawa . Wilayah RT 37 terdiri dari daratan dan dekat dengan anak sungai Batang hari Jambi. RT 037 berbatasan dengan :Sebelah Utara :RT.19 dan RT.41. Sebelah Selatan :Anak Sungai Batang hari. Sebelah Timur : RT.20, Sebelah Barat: RT.28. 
Survei awal pada bulan Januari 2021 , salah satu warga mengatakan jarang dilakukan penyuluhan oleh Pihak Puskemas dan sebagian masyarakat masih terbiasa melakukan pola hidup tidak sehat seperti kebiasaan merokok pada Pria, kurang olahraga, sering mengkonsumsi makanan yang berlemak, dan kurang memahami bagaimana pencegahan hipertensi. Dari uraian diatas maka kami tertarik untuk melakukan kegiatan pengabdian masyarakat dengan judul "Penerapan Diet Hipertensi pada masyarakat Kelurahan Legok Kota Jambi “.

\section{TARGET DAN LUARAN}

Target dalam pengabdian ini adalah setelah dilakukan edukasi, $90 \%$ peserta dapat memahami serta mau menerapkan Diet Hipertensi. Masyarakat memahami penatalaksanaan dan upaya pencegahan hipertensi serta mampu menyusun menu sehat hipertensi

\section{METODE PELAKSANAAN}

Tujuan pengabdian ini diharapkannya keluarga dapat mengetahui apa itu penyakit hipertensi ,bagaimana upaya pencegahan serta Penerapan Diet Hipertensi pada masyarakat Kelurahan Legok Kota Jambi. Penyuluhan dilaksanakan pada hari Senin, 12 April 2021, Pukul 09.30 wib s/d s elesai di Pos Kamling RT 037 Kel. Legok Danau Sipin. Peserta yang mengikuti sebanyak 15 orang. Jumlah Mahasiswa yang terlibat dalam penyuluhan sebanyak 4 orang.

Metode yang digunakan ceramah, diskusi/tanya jawab dengan media leaflet dan modul, alat pemeriksaan fisik yaitu Tensimeter

\section{HASIL DAN PEMBAHASAN}

Kegiatan ini dibantu oleh mahasiswa/i program studi D3 Keperawatan. Kegiatan penyuluhan ini bertujuan agar warga memahami tentang manfaat/pentingnya pentingnya pencegahan hipertensi serta diet hipertensi. Pada pengabdian masyarakat ini tim juga melaksanakan pengukuran tekanan darah. Kegiatan penyuluhan berlangsung kurang lebih 50 menit dan terlaksana dengan tertib dan lancar serta mendapat sambutan yang baik oleh warga dan RT. Evaluasi yang diperoleh setelah penyuluhan warga mampu memahami tentang apa yang dimaksud dengan pengertian hipertensi, penyebab, gejala, penatalaksanaan dan upaya pencegahan hiperetensi, serta mampu memahami pengaturan pola makan/diet sehingga terhindar dari hipertensi. Pada pemeriksaan tekanan darah ditemukan 6 warga yang menderita Hipertensi, sehingga disampaikan kepada mereka untuk selalu mengontrol tekanan darah ke pelayanan kesehatan terdekat dan selalu menjaga pola hidup sehat, diet seimbang.

Pengabdian masyarakat sebelumnya juga telah dilaksanakan oleh tim dengan tema Tatalaksana Hipertensi. Hasil yang diperoleh adalah masyarakat desa Penegah khususnya lansia mampu memahami tentang tatalaksana hipertensi dan pencegahan Hipertensi, mampu melaksanakan Latihan Senam Hipertensi dan sebagian warga memperoleh Pemeriksaan Tekanan darah(Fatmawati et al., 2019).

Salah satu upaya pencegahan komplikasi hipertensi yaitu dengan melakukan kontrol tekanan darah secara berkala (American Heart Association/AHA (2014). Pengontrolan tekanan darah dan pencegahan komplikasi hipertensi dipengaruhi oleh beberapa faktor antara lain pengetahuan tentang hipertensi dan pola makan dari penderita tersebut (Alexander, 2014). Pengaturan diet hipertensi sangat membantu dalam manajemen hipertensi. Perilaku diet hipertensi yang direkomendasikan oleh DASH (DietaryApproach to Stop Hypertension) untuk penderita hipertensi adalah diet rendah garam, diet rendah kolesterol dan lemak jenuh, diet rendah kalori, 
meningkatkan makanan yang mengandung serat dan tinggi kalium, mengurangi berat badan jika obesitas, tidak merokok, mengurangi minuman yang mengandung alkohol dan melakukan aktifitas fisik (National Heart, Lung, \& Blood Institute, 2011)

Edukasi / promosi kesehatan merupakan upaya yang dilakukan terhadap masyarakat sehingga masyarakat mau dan mampu untuk memelihara serta meningkatkan kesehatan dirisendiri (Notoatmodjo, 2010). Penanganan non farmakologis untuk menurunkan hipertensi juga dapat dilakukan dengan terapi komplementer seperti relaksasi otot progresif, meditasi, aromaterapi, terapi herbal, atau terapi nutrisi/diet (Purwanto, 2013).
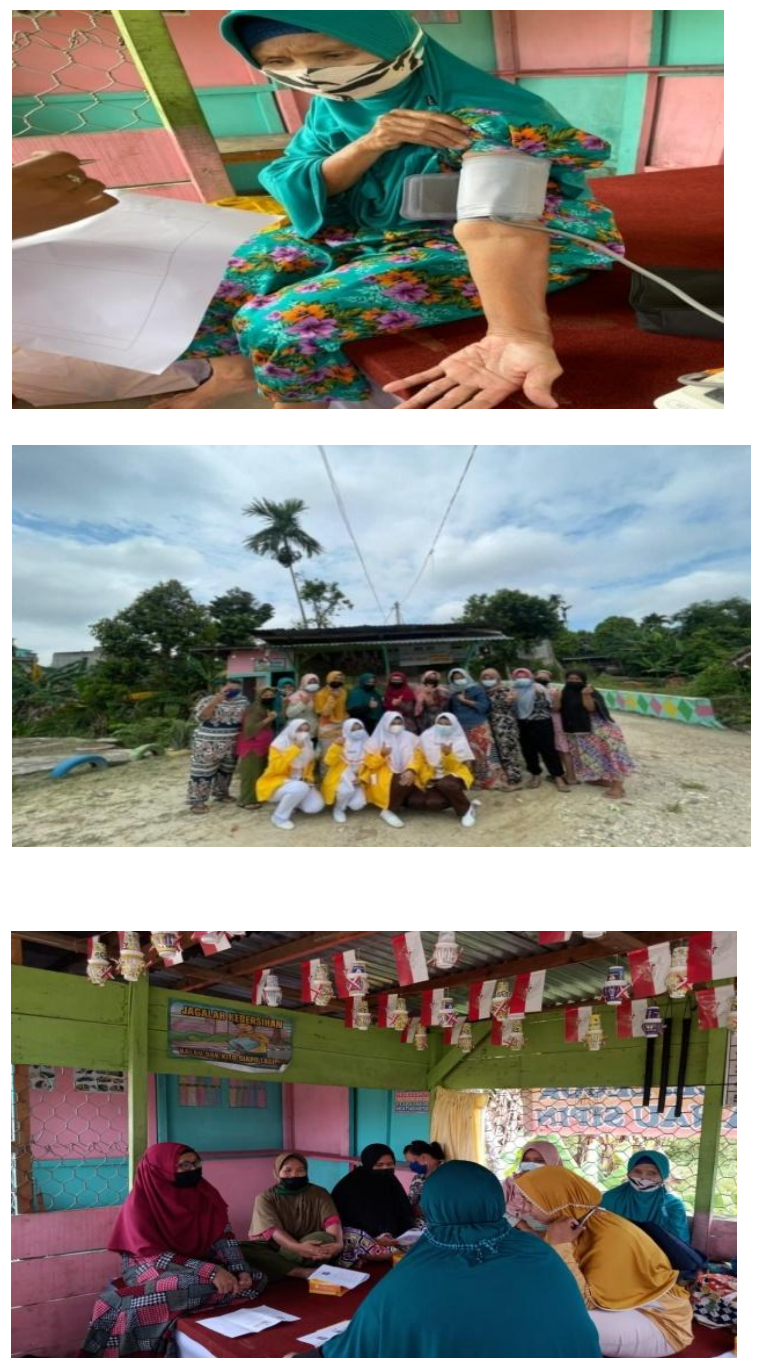

Gambar 1,2,3.Kegiatan edukasi dan pemeriksaan tekanan darah

\section{KESIMPULAN DAN SARAN}

\section{Kesimpulan}

Pengaturan pola hidup sehat sangat penting guna mencegah terjadinya serangan hipertensi. Pencegahan hipertensi dilakukan selain dengan memperhatikan pola hidup sehat seperti mengatur pola makan, tidak merokok, menghindari stress, juga melakukan aktifitas fisik seperti senam, jalan santai, dan selalu melakukan cek tekanan darah secara berkala ke petugas kesehatan terdekat.

\section{Saran}

Diharapkan kepada Tenaga Puskesmas dapat meningkatkan kegiatan promosi kesehatan khusunya dalam pencegahan hipertensi dan pola makan sehat pada penderita hipertensi

\section{DAFTAR PUSTAKA}

Ardiansyah, 2012.Medikal Bedah. Yogyakarta.

Alexander et al, 2014 Patient Knowledge and Awareness of Hypertension IsSuboptimal: Results From a Large Health Maintenance Organization. TheJournal of ClinicalHypertension. 5. 254-260.

American Heart Asosiasion (AHA). (2014). An Effective Approach to High BloodPressure Control

Clark, J. L., Zahradka, P., \& Taylor, C. G. (2015). Efficacy of flavonoids in themanagement of high blood pressure. Nutrition reviews, 73(12), 799-822

Junaidi, I. 2010. Hipertensi. Buana Ilmu Popular. Jakarta.

Kemenkes RI. 2018, RISKESDAS 2018. Jakarta 
Kementerian Perdagangan Republik Indonesia. 2014. Obat Herbal Tradisional.

DitjenPEN/MJL/005/9/2014. Warta Ekspor. Jakarta.

Kemenkes RI. Pelayanan dan Peningkatan Kesehatan Usia Lanjut. Diakses pada tanggal12Maret2017melaluihttp://ww w.depkes.go.id/article/view/15052700 010/pelayanan-dan-peningkatankesehatan-usia-lanjut.html

Kumar, S. S., Manoj, P., \& Giridhar, P. (2015). Fourier transform infrared spectroscopy(FTIR) analysis, chlorophyll content and antioxidant properties of native anddefatted foliage of green leafy vegetables. Journal of food science andtechnology, 52(12), 8131-8139.

Maimaznah, M., \& Fatmawati, T. Y. (2020). Lansia Sehat Bebas Hipertensi di Kelurahan Kenali Asam Bawah Kota Jambi. Jurnal Abdimas Kesehatan (JAK), 2(1), 81. https://doi.org/10.36565/jak.v2i1.100

Mamitoho, R. F., Sapulete, I. M., \& Pangemanan, D. H. (2016). Pengaruh senam lansiaterhadap kadar kolesterol total pada lansia di BPLU Senja Cerah Manado. Jurnale-Biomedik, 4(1).Moniaga, V. (2013). Pengaruh Senam Bugar Lansia Terhadap Tekanan Darah Penderita Hipertensi Di BPLU Senja Cerah Paniki Bawah. Jurnal e-Biomedik, 1(2).

Notoatmodjo, S. 2012. Promosi Kesehatan dan Perilaku Kesehatan. Penerbit RinekaCipta. Jakarta. National Institute for Health and Clinical Excellence. (2011). Hypertension: clinicalmanagement of primary hypertension in adults.

National Institute for HealthandClinical ExcellencePrice SA, Wilson LM. 2012. Patofisiologi konsep klinis proses-proses penyakit, edisi ke-6. Jakarta : EGC13
Purwanto, B. 2012. Hipertensi (Patogenesis, Kerusakan Target Organ danPenatalaksanaan). Edisi Pertama. Cetakan Pertama. UPT Penerbitan danPercetakan UNS (UNS press).

Rahajeng, E, 2009. Prevalensi Hipertensi dan Determinannya di Indonesia. Jakarta

Organization (WHO). (2013). A global brief on hypertension: silentkiller,global public health crisis. World Health Organization

Susilo, Y, Wulandari, A, 2011.Cara Jitu Mengatasi Darah Tinggi (Hipertensi). Yogyakarta

Fatmawati, T. Y., Diii, P., Stikes, K., \& Jambi, B. (2019). UPAYA

PENCEGAHAN HIPERTENSI DI DESA PENEGAH KECAMATAN PELAWAN KABUPATEN SAROLANGUN JAMBI. Jurnal Abdimas Kesehatan (JAK), 1(2). https://doi.org/http://dx.doi.org/10.365 65/jak.v1i2.30

Wahdah, N. (2011). Menaklukan hipertensi dan diabetes: mendet 